\title{
Untypical Draining Barriers Efficiency as a Method of Pollutants Limiting in the Groundwater Reservoir
}

\author{
Agnieszka Operacz ${ }^{1 *}$, Karolina Kurek ${ }^{1}$, Dariusz Młyński', Piotr Bugajski ${ }^{1}$ \\ 1 University of Agriculture in Krakow, Faculty of Environmental Engineering and Land Surveying, Department \\ of Sanitary Engineering and Water Management. Al. Mickiewicza 21, 31-120 Kraków, Poland \\ * Corresponding author's e-mail: a.operacz@urk.edu.pl
}

\begin{abstract}
The main aim of the paper was to formulate a proposal of using the draining barriers as a method of limiting pollutants in the groundwater reservoir. Primary processes of pollutants migration and examples of functioning the draining barriers work against the spread of various pollutants in the groundwater were indicated. An untypical kind of draining barrier, i.e. wells which were designed as a hydrogeological borehole to exhaust water intended for consumption, was selected as the research object. For analytical purposes, the available archival results of the physicochemical analysis of groundwater exhausted from the wells, located in the water intake so-called "belt D" in Kraków-Nowa Huta were used. The database was analysed by specialist programs, and the dispersion migration of pollutants from the existing metallurgical waste dump "Ruszcza" in time was presented. Temporary and spatial variability of the physicochemical parameters of groundwater was done during the analysis. The analysis was performed both in the draining barriers wells and in the intake boreholes. A geostatistical analysis of the variability of pollutant spread in the groundwater medium was a vital factor in the appraisal efficiency of the draining barriers operation. It was shown that the highest contents of the researched substances were present in the wells, which are located the nearest of metallurgical waste dump "Ruszcza" and are thereby the wells co-forming draining barriers. The efficiency of draining barriers was found after a thorough analysis.
\end{abstract}

Keywords: groundwater, pollution, draining barrier, pumping

\section{INTRODUCTION}

Groundwaters offer the best physicochemical and bacteriological properties and thus they should be provided with the highest form of protection. About $40 \%$ of the drinking water comes from groundwater, about $97 \%$ of the rural population drinks groundwater, and about $30-40 \%$ of the water used for agriculture comes from groundwater [Sharma and Reddy 2004]. A steadily growing anthropogenic pressure on groundwater resources creates a conflict situation between nature and man which are competing for clean and safe sources of water [Żurek et al. 2015]. This is caused by the increasing inputs of contaminants to our global water resources, posing a serious risk to human health and ecosystem functions [Balderacchi et al. 2013; Schwarzenbach et al. 2010]. A growing interest is now observed in the methods of stopping or reversing the progressing degradation of the soil and water environment, mainly caused by anthropogenic pressure. Since the end of the 20th century, a rapid development of effective remediation has been observed, although optimization is still necessary. Treating the soil and groundwater environment, unlike surface water treatment (where technology is largely recognized), is a challenge for environmental engineering. High consciousness of groundwater contamination is reflected in the environmental legislation of the European Union [Kløve et al. 2011a and 2011 b; EC 2000 and 2006]. A systematic approach for the assessment and remediation of contaminated sites is necessary in order to facilitate the remediation process and avoid undue delays. The most important aspects of the approach include site characterization, risk assessment, and selection of an effective remedial action [Sharma and Reddy 
2004]. Innovative integration of various tasks can often lead to a faster, cost-effective remedial program [Reddy 2008]. The activities related to the elimination of pollutants include isolation of pollutants, control of their spread, or their complete elimination. If the groundwater contamination is confirmed and remedial action is deemed necessary following a thorough site characterization and risk assessment, one of many remedial technologies may be utilized for corrective action. The most common physical and chemical remediation technologies are pump and treat, in-situ air sparging, in-situ flushing, and permeable reactive barriers [Reddy 2008].

\section{STUDY OBJECTIVE}

The main objective of the study was to analyse the effectiveness of using the existing drainage barrier as a non-standard way to reduce the migration of pollutants in the hydrogeological centre. The water intake in the so-called belt $\mathrm{D}$ of ArcelorMittal Steelworks in Krakow-Nowa Huta currently working partly as a barrier, and partly still in accordance with the original function as a drinking water intake was taken as an example of an existing and functioning barrier. For analytical purposes, the results of physicochemical analyses of water from a dozen or so wells were used to form a shot of the metallurgical plant made by the laboratory. Spatial and temporal variations of the physicochemical parameters of water in intake-wells and working as a protective barrier were compared.

\section{CHARACTERISTICS OF THE RESEARCH AREA}

The selection of the research area was dictated by the impact of the "Ruszcza" metallurgy waste landfill. This heap, belonging to the steelworks of ArcelorMittal Poland SA, is an unplugged and unsealed facility. The landfill covers an area of around 26 ha and it is estimated that more than 10 million tonnes of waste have been deposited on it. Due to the considerable diversity of the surface, tightness, capacity, thickness of stored waste, operational period, etc. landfills are one of the most difficult engineering constructions [RosikDulewska and Karwaczyńska 2010]. The Ruszcza landfill has not been in operation for over 40 years. The storage elements are solid rainfalls and liquid waste from the cold rolling mill and the coke-chemical plant. Among the waste, one can distinguish greases, tar, oils, naphthalene, blastfurnace and martens slag. The particularly hazardous liquid waste is meconium, which is very soluble in water.

The research area is located on the left-bank high terrace of the Vistula River in the north-eastern part of Krakow. It lies between the Carpathian Foredeep Basin and the Nidzianska Basin. The Carpathian Foredeep Basin is a vast tectonic depression filled with silty clays of the Miocene age, with a thickness of up to $600 \mathrm{~m}$, which is found on the limestone of the Cretaceous or the Jurassic period. The works that distinguish the Miocene period are concise. In the case of the Miechów Basin, the sub-Quaternary subsoil is formed by crevice marly chalks with a thickness of several dozen meters (Fig. 1). In the area of research, the Miocene deposits constitute an impermeable foundation for the Pleistocene aquifer with a variable thickness between 5 and $16 \mathrm{~m}$. The Pleistocene deposits form sand and gravel complexes in their bottom part. The peak part of the Pleistocene profile is made of a complex of loess sediments that are poorly permeable.

The geological structure of the research area is important in the assessment of the infiltration conditions and the level of groundwater hazard. The penetration of contaminants from the heap constitutes a threat to the aquifer (Figure 2). The migration of pollutants is favoured by the relatively low thickness of the Pleistocene formations and the share of weak and well-permeable gravel-sandy complexes.

In the area covered by observations there is only one Pleistocene aquifer of a continuous nature. The aquifer includes gravel and sand. The main part of this layer is made up of impermeable Miocene clays. The roof of the aquifer is semipermeable loess dust with a thickness from a few to a dozen or so meters. In the area of the "D" belt, the water table is free. This level is fed mainly by underground runoff and infiltration of atmospheric precipitation. The value of the filtration coefficient ranges from $1.83 \cdot 10^{-4}$ to $7.70 \cdot 10^{-4} \mathrm{~m} \cdot \mathrm{s}^{-1}$. Groundwater flows generally in the south, while in the area of the ArcelorMittal smelter - to the centre of the depression hopper (Fig. 2).

In the analysed area, there is a functioning groundwater intake for the needs of the metallurgical plant of ArcelorMittal Poland S.A. The 


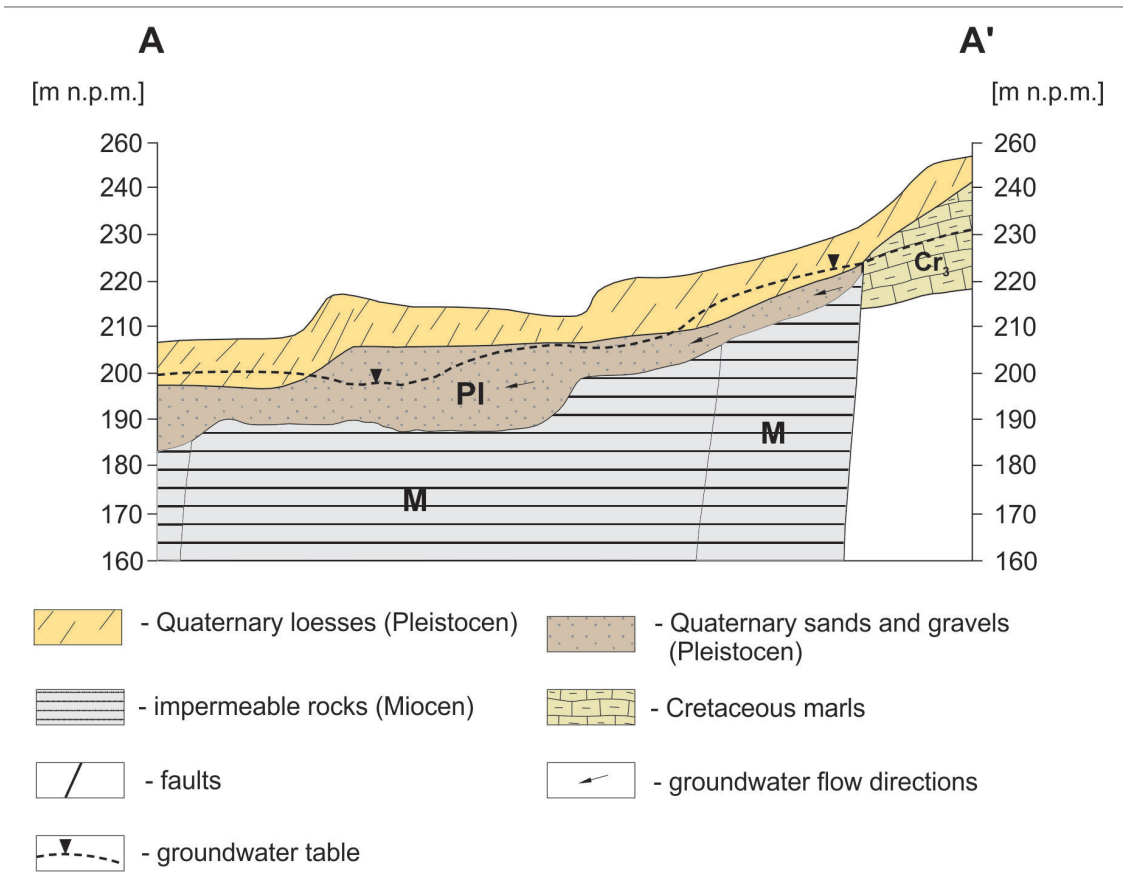

Figure 1. Schematic cross-section of the study area (section line in Fig. 2)

shot consists of 13 drilled wells (Fig. 2), seven of which constitute the intakes of water for consumption: S-1A, S-2A, S-8A, S-9/83, S-10A, S-11A and $\mathrm{S}-13$. The remaining wells are excluded from the use of water for drinking purposes and act as a protective barrier ( $\mathrm{S}-3$ ', S-4/83, S-5A, S-6A, $\mathrm{S}-7 \mathrm{~B}$ and S-12). In the case of the "D" belt, the variability of the operating efficiency is observed due to the colmatization and overgrowth of the well filters due to the natural elevated content of iron and manganese. This phenomenon is connected with the necessity of replacing the incorrectly working wells by creating new wells (well-received well gets A). In the text and in the drawings, the simplified naming of the well was adopted. The depth of the drilled wells in question ranges from 20.0 to $30.0 \mathrm{~m}$. Table 1 lists the basic characteristics of the boreholes. All the wells that make up the area of the intake were originally designed as the openings enabling the consumption

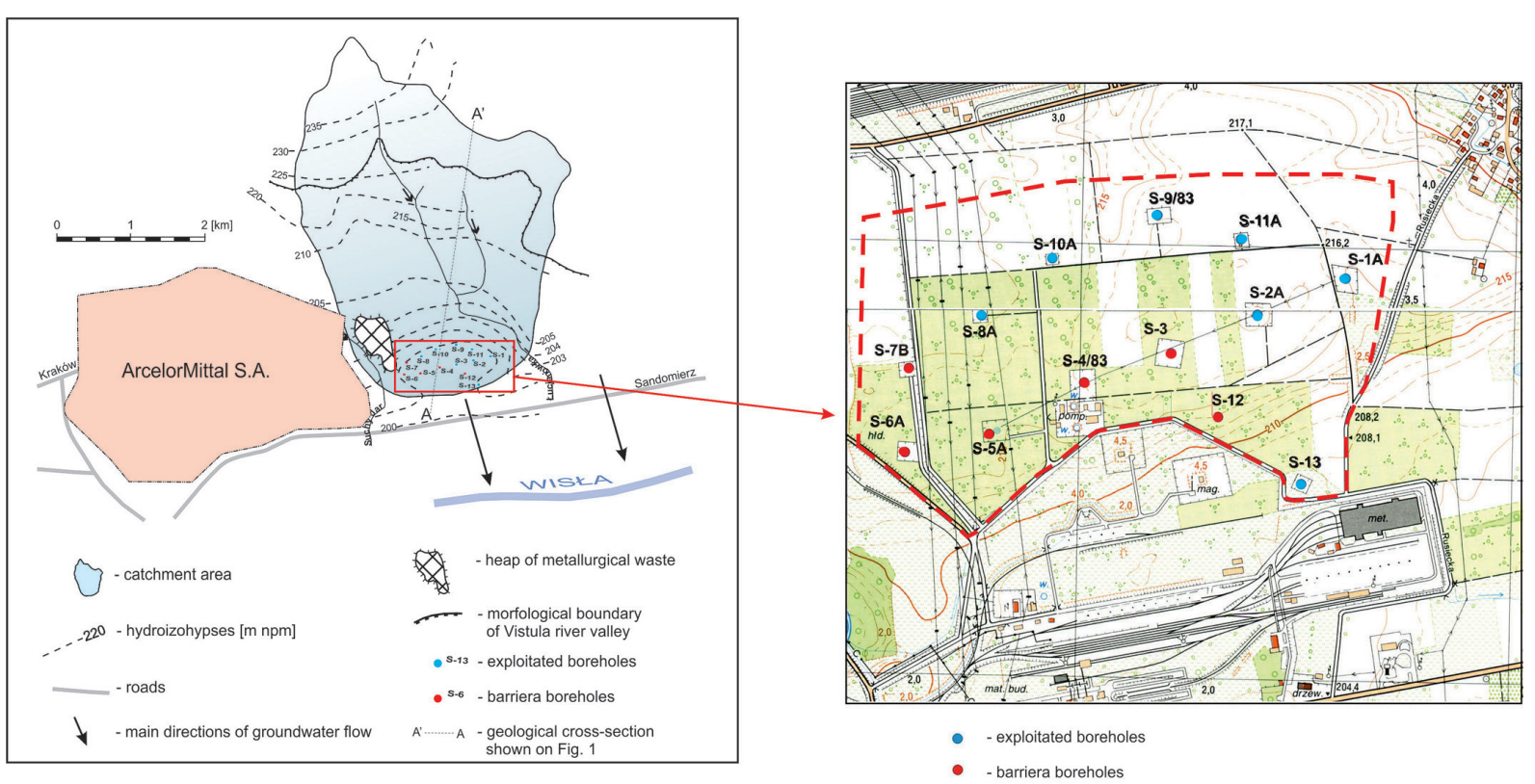

Figure 2. Map of hydroizohips and deployment of the wells of the "D" belt approach [Zuber et al. 1985 - modified] 
of drinking water. Currently, the water exploited with barrier wells is discharged to the Suchy Jar canal and goes to the Vistula. Barrier wells enable the work of the shot as a result of interception of the stream of pollutants flowing into the centre of the depression funnel. Due to the high content of iron and manganese compounds in the groundwaters, a water treatment station was built.

\section{RESEARCH METHODOLOGY}

The leachates from the heaps infiltrating into the aeration zone, and then migrating to groundwater (Fig. 3), worsen their quality. The inflow of groundwater to the centre of the depression hopper caused by their exploitation creates a real risk of losing the required quality and the inability to use them for consumption.

The impurities from the landfills were observed at the earliest in well no. 6 (Fig. 2) by a rapid increase in oxidation to $28 \mathrm{mg} \mathrm{O}_{2} \cdot \mathrm{dm}^{-3}$, while in other wells, the natural level of oxidation was only $1 \mathrm{mg} \mathrm{O} \cdot \mathrm{dm}^{-3}$. In the part of the intake adjacent to the heap, phenols appeared a year after the observed changes. In order to protect against the further spread of pollutants, it was decided to continue pumping water from well no. 6 under the conditions of discharge of contaminated water to the combined sewerage system. The status of a well from the intake side to the barrier (protective) well has changed.

Subsequent changes in the chemical composition of waters were observed in the neighbouring wells S-5 and S-7. The wells numbered S-4, S-3 and $\mathrm{S}-12$ were excluded from the basic function of the intake and just performed the protective barrier function. There was an increase in dry residue above $1000 \mathrm{mg} \cdot \mathrm{dm}^{-3}$, iron concentration around $9 \mathrm{mg} \cdot \mathrm{dm}^{-3}$, manganese up to $5 \mathrm{mg} \cdot \mathrm{dm}^{-3}$ and sulphates up to $450 \mathrm{mg} \cdot \mathrm{dm}^{-3}$. On the basis of the results of the monitoring of groundwater quality in the area of the " $D$ " belt managed by the ArcelorMittal steelworks, it was possible to assess the work of the well. The analysis covered a 13-year period. The parameters indicating the

Table 1. List of wells of the belt D

\begin{tabular}{|c|c|c|c|c|c|c|c|c|c|c|}
\hline \multirow[b]{2}{*}{$\begin{array}{c}\text { No. of } \\
\text { well }\end{array}$} & \multicolumn{2}{|r|}{ Well } & \multicolumn{4}{|c|}{ Groundwater level } & \multirow{2}{*}{\begin{tabular}{|c|} 
Filter \\
Diameter \\
[mm] \\
from-to \\
{$[\mathrm{m}]$} \\
\end{tabular}} & \multirow[b]{2}{*}{$\begin{array}{c}\text { Pumping test } \\
\text { (the last level) } \\
\text { efficiency }\left[\mathrm{m}^{3} / \mathrm{h}\right] \\
\text { depression }[\mathrm{m}]\end{array}$} & \multirow[b]{2}{*}{$\begin{array}{c}\text { Filtration } \\
\text { coefficient } \\
{[\mathrm{m} / \mathrm{d}]}\end{array}$} & \multirow[b]{2}{*}{ Comments } \\
\hline & Year & $\begin{array}{c}\text { Depth } \\
{[\mathrm{m}]} \\
\text { statigraphy of } \\
\text { the bottom }\end{array}$ & $\begin{array}{l}\text { Starti- } \\
\text { graphy }\end{array}$ & $\frac{\text { Upper }}{\text { bottom }}$ & $\begin{array}{c}\text { Effective } \\
\text { thickness } \\
{[\mathrm{m}]}\end{array}$ & $\begin{array}{c}\text { Stabilised } \\
\text { grounwater } \\
\text { table } \\
\text { [m ppt] }\end{array}$ & & & & \\
\hline S-1 & 1998 & $\frac{27.5}{\mathrm{Tr}}$ & Q & $\frac{12.6}{24.3}$ & 11.7 & 12.6 & $19 . \frac{300}{3-24.3}$ & $\frac{47.36}{5.45}$ & 18.3 & $\begin{array}{l}\text { exploitated } \\
\text { well }\end{array}$ \\
\hline S-2 & 1999 & $\frac{30.0}{\mathrm{Tr}}$ & Q & $\frac{15.25}{27.8}$ & 12.55 & 15.25 & $\frac{300 / 315}{23.0-28.0}$ & $\frac{36.0}{4.15}$ & 15.8 & $\begin{array}{l}\text { exploitated } \\
\text { well }\end{array}$ \\
\hline S-3 & 1972 & $\frac{28.46}{\mathrm{Tr}}$ & $Q$ & $\frac{16.63}{26.0}$ & 9.37 & 16.63 & $\frac{820}{20.96-25.96}$ & $\frac{46.5}{4.23}$ & 66.5 & $\begin{array}{l}\text { barrier wel } \\
\text { from } 1999\end{array}$ \\
\hline S-4 & 1983 & $\frac{30.0}{\mathrm{Tr}}$ & Q & $\frac{14.25}{26.5}$ & 12.25 & 14.25 & $\frac{229}{21.5-26.5}$ & $\frac{31.3}{3.15}$ & 19.4 & barrier wel \\
\hline S-5 & 1968 & $\frac{29.0}{\mathrm{Tr}}$ & Q & $\frac{13.36}{26.2}$ & 12.84 & 13.36 & $20.0 \frac{229}{26.0}$ & $\frac{65.49}{4.28}$ & 33.3 & barrier wel \\
\hline S-6 & 1997 & $\frac{28.5}{\mathrm{Tr}}$ & Q & $\frac{13.8}{25.0}$ & 11.2 & 13.8 & $21 \frac{300}{20-25.0}$ & $\frac{48.0}{5.15}$ & 21.6 & barrier wel \\
\hline S-7 & 1985 & $\frac{29.0}{\mathrm{Tr}}$ & Q & $\frac{16.0}{26.0}$ & 10.0 & 16.0 & $\frac{299}{21.5-26.0}$ & $\frac{64.3}{4.9}$ & - & barrier wel \\
\hline S-8 & 1999 & $\frac{28.5}{\mathrm{Tr}}$ & Q & $\frac{15.4}{25.5}$ & 10.1 & 15.4 & $\frac{300 / 315}{20.5-25.5}$ & $\frac{37.0}{4.4}$ & 20.0 & $\begin{array}{c}\text { exploitated } \\
\text { well }\end{array}$ \\
\hline S-9 & 1983 & $\frac{30.0}{\mathrm{Tr}}$ & $\mathrm{Q}$ & $\frac{13.4}{26.5}$ & 13.1 & 13.4 & $\frac{229}{21.5-26.5}$ & $\frac{51.42}{4.32}$ & 25.3 & $\begin{array}{c}\text { exploitated } \\
\text { well }\end{array}$ \\
\hline S-10 & 1999 & $\frac{30.0}{\mathrm{Tr}}$ & $\mathrm{Q}$ & $\frac{14.4}{27.0}$ & 12.6 & 14.4 & $\frac{300 / 315}{22.0-27.0}$ & $\frac{60.0}{4.9}$ & 24.7 & $\begin{array}{c}\text { exploitated } \\
\text { well }\end{array}$ \\
\hline S-11 & 1986 & $\frac{29.4}{\mathrm{Tr}}$ & Q & $\frac{15.4}{26.5}$ & 11.1 & 15.4 & $21 \frac{356}{9-26.4}$ & $\frac{34.0}{2.8}$ & 28.2 & $\begin{array}{c}\text { exploitated } \\
\text { well }\end{array}$ \\
\hline S-12 & 1986 & $\frac{24.8}{\mathrm{Tr}}$ & $\mathrm{Q}$ & $\frac{12.5}{21.8}$ & 9.3 & 12.5 & $17 . \frac{356}{3-21.8}$ & $\frac{32.7}{3.7}$ & 27.7 & barier well \\
\hline$S-13$ & 1986 & $\frac{20.0}{\mathrm{Tr}}$ & Q & $\frac{7.0}{17.0}$ & 10.0 & 7.0 & $12 \frac{356}{5-17.0}$ & $\frac{31.0}{4.3}$ & 24.6 & $\begin{array}{l}\text { exploitated } \\
\text { well }\end{array}$ \\
\hline
\end{tabular}


impact of the heap of metallurgical wastes on the waters of the quaternary aquifer, covering the area of the "D" belt, i.e. dry general residue, electrolytic conductivity and sulphates, were selected for the assessment. According to the assumptions, the analysis of the spatial variability of the physicochemical parameters of groundwater was aimed at demonstrating the effectiveness of the atypical drainage barrier to protect water quality in the wells of the " $D$ " belt. In the course of generating isoline maps for further spatial analysis, the kriging method was chosen as the technique yielding more realistic and reliable spatial distributions. It was found that the method of squares inverse distances generates little real isolation of isolines around extreme values, thus creating the surfaces that do not correspond to reality. The method of kriging is considered by many scientists to be the best when interpolating heterogeneous natural phenomena [Pawlowsky-Glahn and Buccianti 2011]. During the preparation of the isoline maps, the isotropy of the aquifer and the continuity of occurrence of the analysed chemical components were assumed. Four maps were made for each component, taking an individual appropriate time step for them. By proceeding to data analysis, two independent samples were compared. The wells forming the intake of the so-called the " $\mathrm{D}$ " belt was divided into two groups, taking into account the functions they perform. The first group consisted of the wells that included drinking water, while the wells working as a drainage barrier were assigned to the second group. In the next step, normality tests were carried out using statistical tests: Kolmogorow-Smirnov K-S, Lilliefors, and W Shapiro-Wilk [Filzmoser and Hron 2009]. In each case analysed, the distribution differed significantly from the normal one. After the normality tests, the Mann-Whitney U test was performed. Due to insufficient data and unsystematic measurements of the analysed parameters, the following two statistical analyses were limited: the Mann-Whitney $U$ test was performed and cluster analysis was carried out [Nachar 2008]. With the concentration data of individual physicochemical parameters for groundwater, a cluster analysis was performed using the k-means grouping method. As a result of the application of this method, a breakup was achieved in which none of the resulting clusters constitute a sub-purchase of another. Each time, in the case of the analysis of selected physicochemical parameters, three concentrations were created.

\section{RESULTS AND DISCUSSION}

\section{Spatial variability of the dry general residue}

The spatial analysis of the variability of dry general residue in belt wells is presented in Fig. 3. The maps of spatial distribution in the 13th research year are shown for 1991, 1993, 2000 and 2004. In the analysed multi-year, the highest concentrations of dry general residue were characterized by the S-5, S-6, and S-7 waters wells directly adjacent to the post-mine waste dump. With the distance from the heap, the concentration of this parameter in the water decreases. While analysing the variability of the dry general residue over the course of several years, it can be clearly stated that the highest increase in this parameter was recorded in the wells acting as a drainage barrier (S5, S6, S7), and the lowest concentration occurred in the wells far from the heaps. In the first years of the analysed period, there is a clear upward trend in the considered parameter in the S-5, S-6, and S-7 wells. Then, the increase of the total dry residue was also observed in the S-3, S-4 and S-12 wells, which together with the abovementioned wells are in one zone. Wells S-1, S-2, S-8, S-9, S-10, S-11, and S-13 are in the second zone, because the value of dry residue in these wells deviates from the value of the parameter in the wells from the first zone.

A plot of the mean of each aggregate for dry general residues is shown in Fig. 4. The S-5, S-6, and S-7 wells forming the protective barrier and located closest to the heap of metallurgical wastes with the highest level of the tested parameter with its increasing tendency were assigned to cluster 1 . The dry general residue content decreases with the next concentration. The S-1 well containing drinking water and S-3, S-4 and S-12 forming a drainage barrier were assigned to cluster 2 . In cluster 3, there are only the wells that include drinking water, i.e. S-2, S8, S-9, S-10, S-11 and $\mathrm{S}-13$. Considering the location of the well in the " $\mathrm{D}$ " belt and the direction of groundwater inflow (Fig. 2), it can be noticed that the wells belonging to cluster 1 have a significant impact on the reduction of dry general residue in the waters of subsequent wells.

It can be stated that there is an important dependence between the contents of the tested parameter in the forming wells a drainage barrier and the wells that include drinking water. It is deduced that the wells of the drainage barrier 


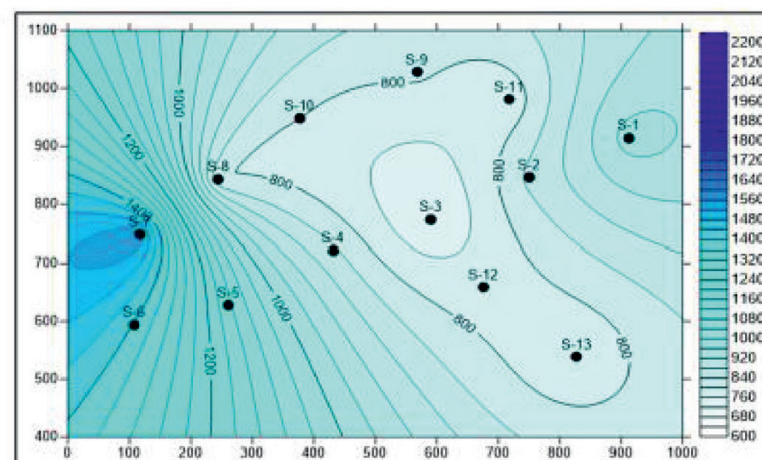

1991 rok

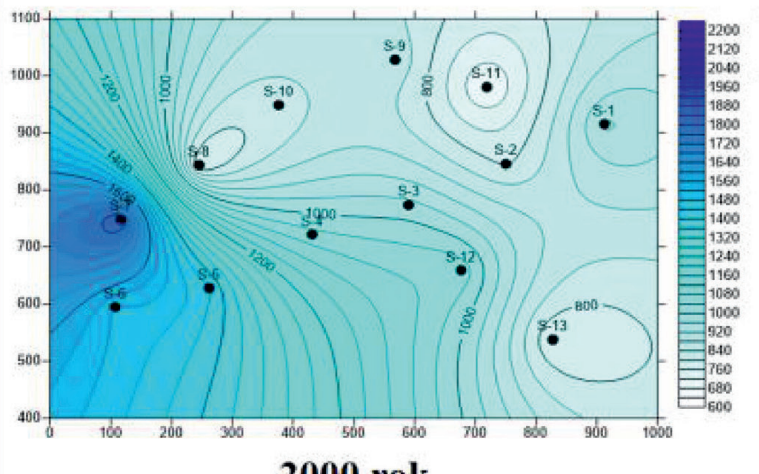

2000 rok

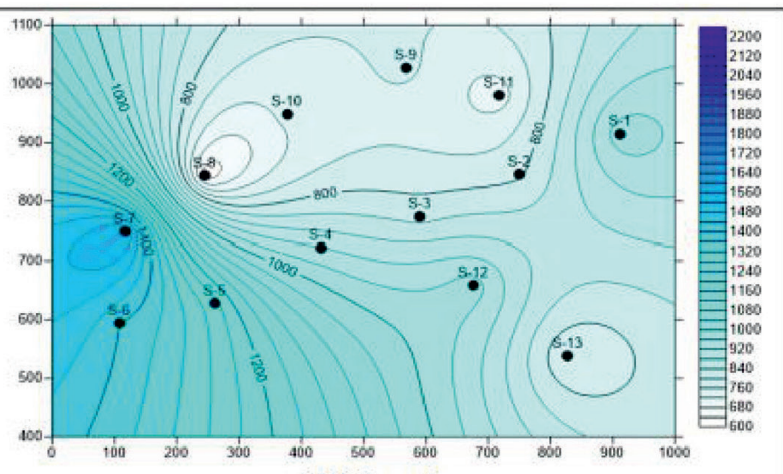

1993 rok

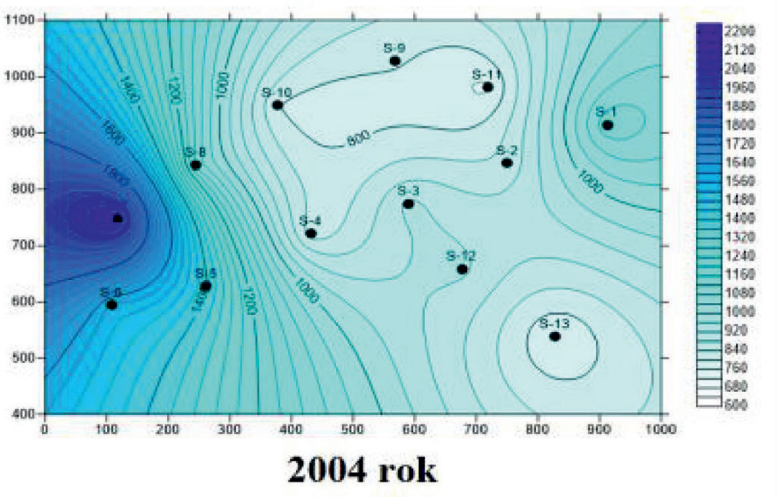

Fig. 3. Spatial variability of dry general residue in groundwater in the area of water intake in D belt

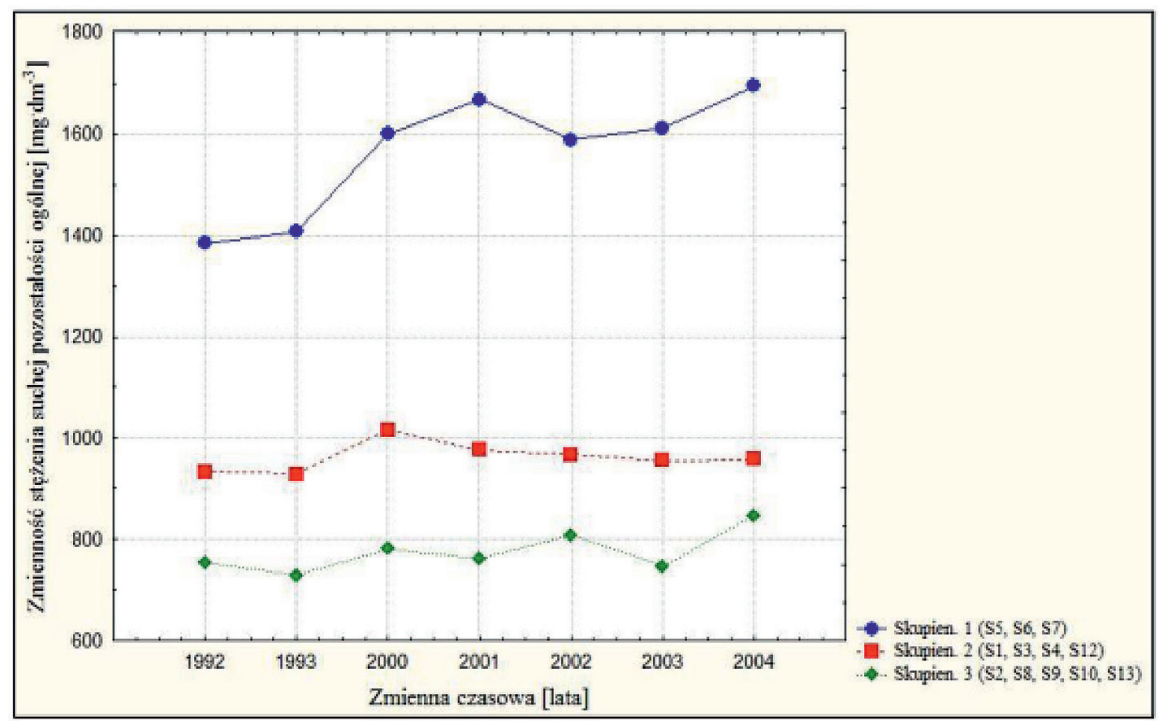

Fig. 4. Diagram of the mean of each cluster for dry general residues

affect the wells belonging to the second group. In this case, the statistical significance of the test at $\mathrm{p}=0.008$ was demonstrated.

\section{Spatial variability of electrolytical conductivity EC}

In the analysed multi-year, the highest content of EC was characterized by the waters coming from the S-4, S-5, S-6, S-7 wells, and in 2004 also the S-1 well. These wells, with the exception of S-1, directly adjoin the stacks of postmetallurgical waste. The increase in EC in the S-1 well indicates a potential contamination with of unidentified origin, which is unlikely to be related to the impact of this dump of metallurgical wastes. Considering the EC of groundwater taken from the belt " $\mathrm{D}$ " in the current years 1991-2004, 
it was shown that the highest EC parameter was recorded in the wells acting as a drainage barrier, and the lowest level of EC occurred in the wells. At the turn of 1999-2004, the highest decrease in the analysed parameter was recorded in S-6 and $\mathrm{S}-12$ wells, which is caused by the decrease in the spread of pollutants due to intensive pumping of contaminated waters by barrier wells. On the spatial distribution maps (Fig. 5), two zones can be seen. There is a clear upward trend in the EC parameter in S-1, S-4, S-5, S-6, S-7, S-12 wells, which is one zone, while S-2, S-8, S-9, S-10, S-11, $\mathrm{S}-13$ wells are in the second zone. The recession of the contaminated zone after 1999, when S-3 and $\mathrm{S}-12$ wells began intensive work as barrier wells is clearly visible.

As in the case of a dry general residue, a relationship was found between the wells forming a protective barrier and the wells that contain water for the purpose of its consumption. The statistical significance of the test was at $p=0.008$. Only S-5, S-6, and S-7 wells were assigned to cluster 1, as in the case of dry general residues. The analysis of Fig. 5 indicates that EC content decreases with the next concentration. One well (S-1) was assigned for water for drinking purposes to cluster 2, while the remaining S-3, S-4 and S-12 are the wells that form a drainage barrier. Cluster 3 includes the S-2, S8, S-9, S-10, S-11, S-13 wells with the lowest value of the tested parameter. Similarly to the dry residue, it is concluded that the wells belonging to cluster 1 significantly affect the reduction of the tested parameter in the waters of subsequent wells.

\section{Spatial variability of sulphate ion content}

Figure 6 shows the spatial variability of the sulphate ion content in terms of the belt D. As in the previous cases, the highest concentrations of sulphates were observed in the immediate vicinity of the waste heap. While analysing the spatial distribution over many years (Fig. 6) it can be seen that in the analysed period from 1991 to 1999 , the sulphate content in the captured groundwater was of an increasing character. The highest concentrations in each considered year were characterized by the waters coming from the wells S-4, S-5, S-6, S-7, and in 1995 and 1999 also in the well S-12. These wells, with the exception of S-12, are directly adjacent to the dump of post-metallurgical waste. In the years 1991-1999, an increase in sulphate ions in each well was noted, and after this period (inclusion of subsequent wells to the barrier) a decrease in the sulphate content (the highest in wells S-4, S-10 and S-12) was noted.

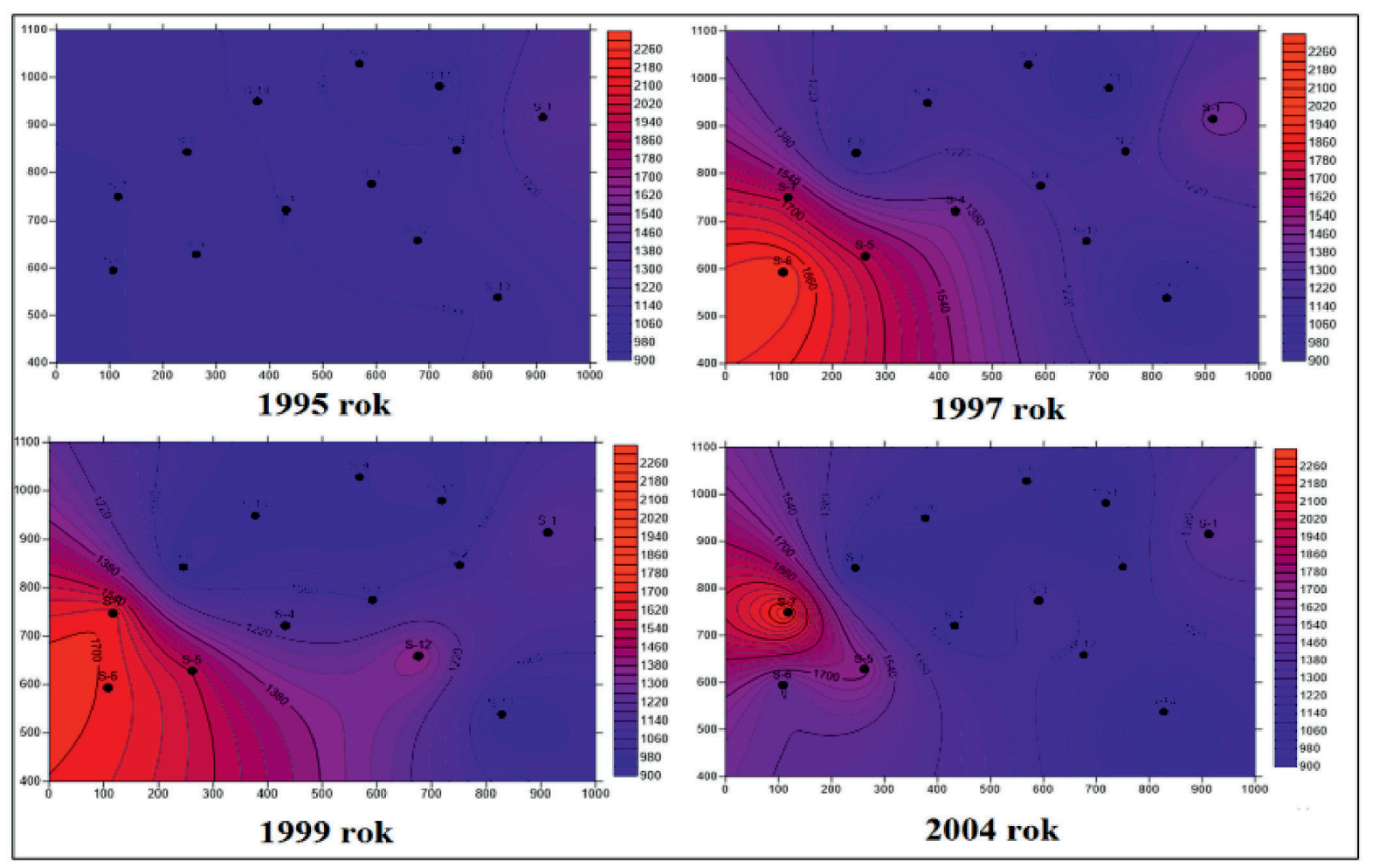

Fig. 5. Spatial variability of electrolytical conductivity in the groundwater in the area of water intake in the belt $\mathrm{D}$ 

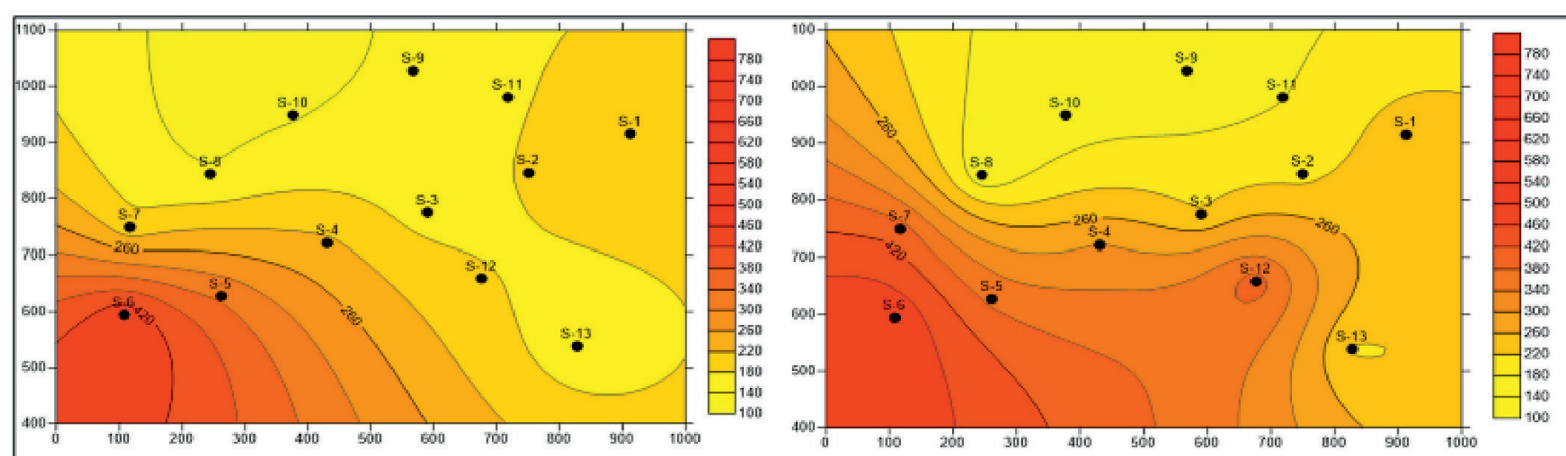

1991 rok

1995 rok
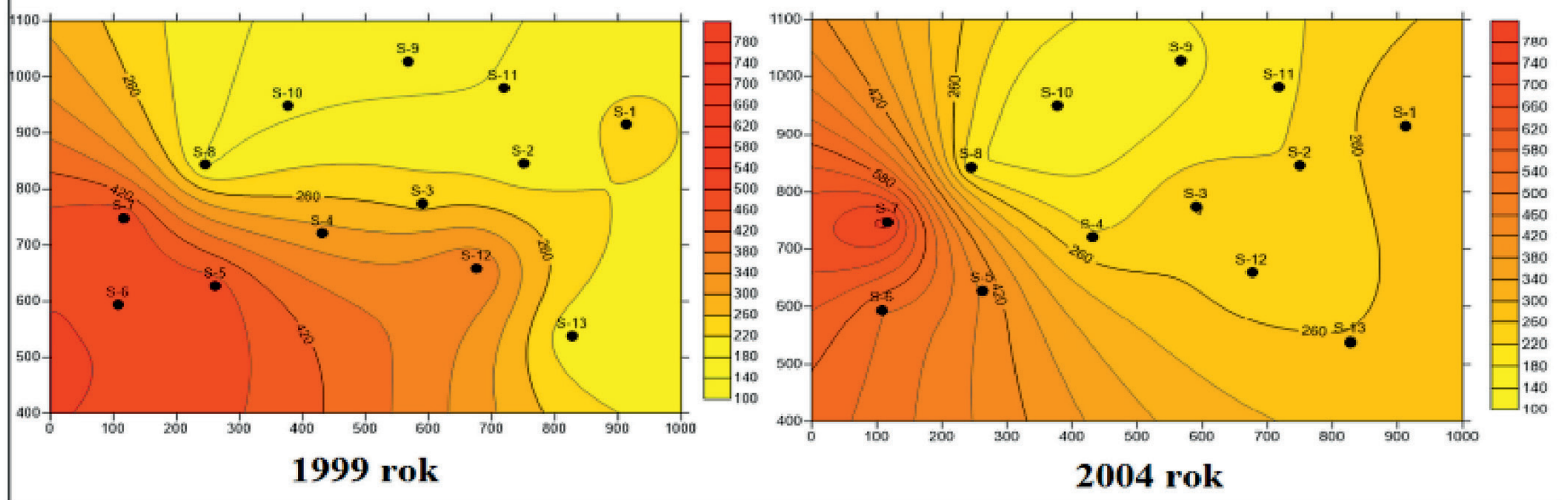

Fig. 6. Spatial variability of sulphate content in groundwater in the area of water intake in the belt D

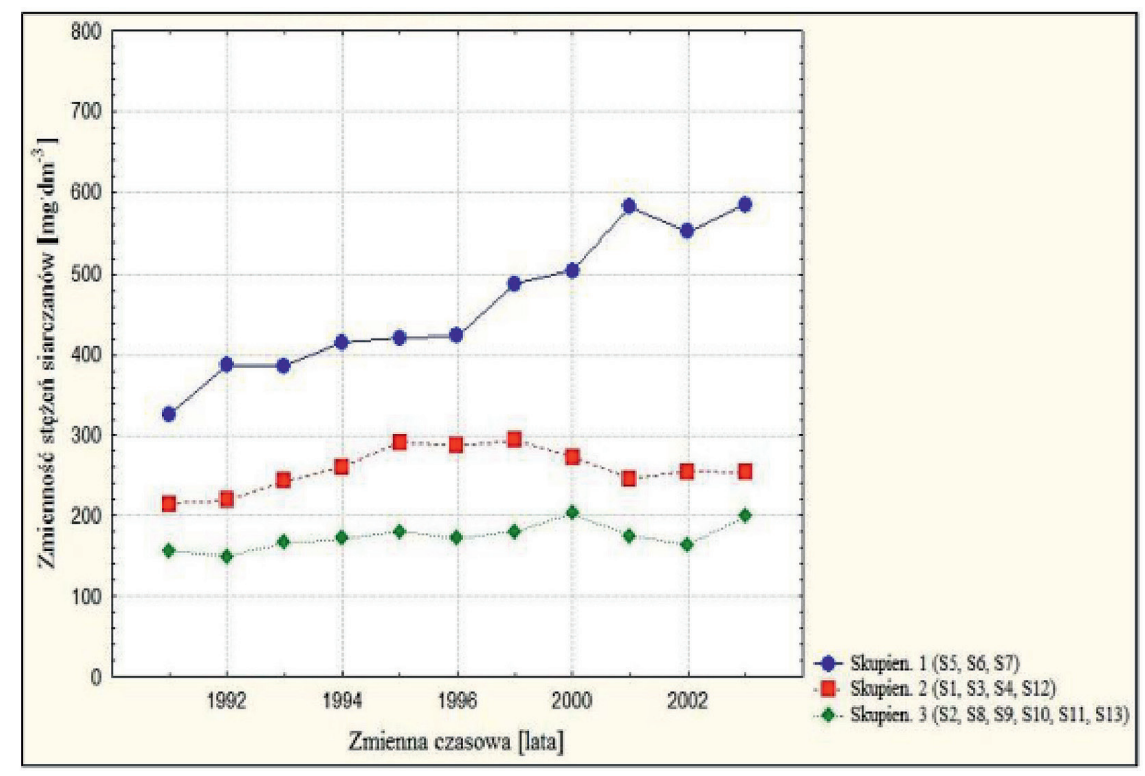

Fig. 7. Diagram of the mean of each cluster for sulphates

Figure 7 is a graph of the mean of each sulphate concentration. Considering the location of the well in the "D" belt and the direction of groundwater inflow (Fig. 2) it can be noticed that the wells belonging to cluster 1 have a significant influence on the reduction of sulphate concentration in the waters of subsequent wells.

\section{CONCLUSIONS}

The emission of pollutants from the unsealed landfills causes that significantly higher concentrations of the analysed physicochemical parameters are recorded in the wells closest to the repository. In order to protect the aquifer, it was decided to change the status 
of the part of the well from the original intake function to the barrier function. The inclusion of further wells into the drainage barrier allowed to pump out and drain the contaminated groundwater to surface watercourses, protecting subsequent wells against the inflow of pollutants. The spatial variability of physicochemical parameters allowed the separation of two areas of the aquifer threat intensity. The first zone includes the wells closest to the waste heap and at the same time the most endangered, working as a protective barrier. The second zone mainly includes the wells in which, through the operation of drainage wells, pollutant concentrations are significantly lower than those observed in the first zone. A statistical analysis showed a clear impact of the work of barrier wells on the quality of groundwater captured by wells.

The change in the function of part of the wells originally made as a shot, on barrier wells, contributed to maintaining low concentrations of the analysed parameters in the wells away from the source of pollution, i.e. from the heaps. The use of an unusual function of multi-hole groundwater intakes (originally designed with the basic operational function) as a barrier limiting the migration of pollutants in the aquifer does not provide a $100 \%$ protection against the further spread of contaminants. This is due to the need to adapt to the original deployment of the well and the reaction to the ongoing migration of pollutants. Nevertheless, the use of the already existing intakes as a protective barrier may constitute a rational solution providing a certain "time buffer" that allows the development of an effective method of removing pollution from the environment.

The implementation of new intakes requires time to obtain relevant permits for their implementation (time of project completion and approval, documentation, obtaining a water permit, etc.). The analysis of the effectiveness of the work of the atypical barrier, i.e. the wells included in the protective barrier, indicates that this type of barrier fulfils its function and although it does not work as effectively as modern barriers, it can be successfully used as one of the techniques limiting the migration of pollutants in a hydrogeological centre in the event of a temporary or financial deficit to take further effective actions.

\section{Acknowledgements}

Publication supported by the Polish Ministryl of Science and Higher Education as a part of the program of activities disseminating science from the project „Organization of the First International Science Conference - Ecological and Environmental Engineering”, 26-29 June 2018, Kraków.

\section{REFERENCES}

1. Żurek A. J., Witczak S., M. Dulinski, P. Wachniew, K. Rozanski, J. Kania, A. Postawa, J. Karczewski, and W. J. Moscicki. 2015. Quantification of anthropogenic impact on groundwater-dependent terrestrial ecosystem using geochemical and isotope tools combined with 3-D flow and transport modelling. Hydrol. Earth Syst. Sci., 19, 1015-1033. doi:10.5194/hess-19-1015-2015

2. Kløve, B., Alaaho, P., Bertrand, G., Boukalova, Z., Ertürk, A., Goldscheider, N., Ilmonen, J., Karakaya, N., Kupfersberger, H., Kværner, J., Lundberg, A., Mileusnic, M., Moszczynska, A.,Muotka, T., Preda, E., Rossi, P., Siergieiev, D., Šimek, J., Wachniew, P., and Widerlund, A. 2011a. Groundwater dependent ecosystems: Part I - Hydroecology, threats and status of ecosystems, Environ. Sci. Pollut. R., 14, 770-781.

3. Kløve, B., Alaaho, P., Allan, A., Bertrand, G., Druzynska, E., Ertürk, A., Goldscheider, N., Henry, S., Karakaya, N., Karjalainen, T.P., Koundouri, P., Kværner, J., Lundberg, A. Muotka, T., Preda, E., Pulido Velázquez, M., and Schipper, P. 2011 b. Groundwater dependent ecosystems: Part II - ecosystem services and management under risk of climate change and land-use management, Environ. Sci. Pollut. R., 14, 782-793.

4. EC: Directive 2000/60/EC of the European Parliament and of the Council establishing a framework for Community action in the field of water policy, OJ L 327, Office for Official Publications of the European Communities, Luxembourg, 2000.

5. EC: Directive 2006/118/EC of the European Parliament and of the Council on the protection of groundwater against pollution and deterioration, OJ L 372, Office for Official Publications of the European Communities, Luxembourg, 2006.

6. Balderacchi M, Benoit P, Cambier P, Eklo OM, Gargini A, Gemitzi A, Gurel M, Klove B, Nakic Z, Preda E, Ruzicic S, Wachniew P, Trevisan M. 2013. Groundwater pollution and quality monitoring approaches at the European level. Crit Rev Environ Sci Technol 43(4), 323-408. https://doi.org/10.1080/10643389.2011.604259

7. Schwarzenbach R, Egli T, Hofstetter TB, von Gunten U, Wehrli B. 2010. Global water pollution 
and human health. Annu Rev Environ Resour 35, 109-136. https://doi.org/10.1146/annurevenviron-100809-125342

8. Sharma, H.D., Reddy, K.R. 2004. Geoenvironmental Engineering: Site Remediation, Waste Containment, and Emerging Waste Management Technologies, John Wiley \& Sons, Hoboken, New Jersey.

9. Reddy K.R., 2008. Physical and Chemical Groundwater Remediation Technologies [in:] C.J.G. in: Darnault (ed.), Overexploitation and Contamination of Shared Groundwater Resources. Springer Science+Business Media B.V. DOI: 10.1007/978-1-4020-6985-7 12

10. Rosik-Dulewska Cz., Karwaczyńska U. 2010. The impactoflocalpointsourcesofpollutiononthequality of underground waters. Prace i Studia Geograficzne. Uniwersytet Opolski, t. 44, 217-232 [in Polish].
11. Zuber A., Kleczkowski A.S., Myszka J., Witczak S. 1985: Efficiency and mineralization of water intake from the Vistula high terrace east of Krakow in the light of isotopic research [w:] Kleczkowski A.S. [red.]. Aktualne Problemy Hydrogeologii, Wyd. AGH Kraków, t. III, 187-196 [in Polish].

12. Pawlowsky-Glahn V, Buccianti A, editors. 2011. Compositional data analysis : theory and applications. Chichester, West SussexUK: Wiley. 400 pp.

13. Filzmoser P, Hron K. 2009. Correlation analysis for compositional data. Mathematical Geosciences 41, 905-919.

14. Nachar N. 2008. The Mann-Whitney U:ATest for Assessing Whether Two Independent Samples Come from the Same Distribution . Tutorials in Quantitative Methods for Psychology, vol. 4(1),p.13-20. http://dx.doi.org/10.20982/tqmp.04.1.p013 